\title{
RASGOS MELÓDICOS DE LAS INTERROGATIVAS DEL ESPAÑOL HABLADO POR BRASILEÑOS
}

\author{
Aline Fonseca de Oliveira \\ Universidade de Brasília \\ aline.fonsecadeoliveira@gmail.com
}

\begin{abstract}
Resumen
Este trabajo presenta algunos de los resultados obtenidos en nuestra investigación, en la que nos proponíamos describir las pautas en la integración fónica del discurso así como los patrones melódicos y márgenes de dispersión del español hablado por brasileños. Los resultados obtenidos a través de nuestro estudio posibilitarán elaborar un mapa de las características entonativas del español hablado por brasileños y con ello se podrá orientar acciones didácticas específicas que puedan perfeccionar la pronunciación del español por parte de los brasileños. En especial, disminuyendo el acento extranjero, clave en la comunicación hispánico brasileña.
\end{abstract}

Palabras clave: entonación, español, portugués, análisis melódico

\section{Resum}

Aquest treball presenta alguns resultats obtinguts a la nostra investigació, on ens proposàvem descriure les pautes de la integració fònica del discurs, així com els patrons melòdics i marges de dispersió de l'espanyol parlat per brasilenys. Els resustats obtinguts al nostre estudi permetran elaborar un mapa dels trets entonatius de l'espanyol parlat per brasilenys, i podrà orientar accions didàctiques específiques que podran perfeccionar la pronúncia de l'espanyol per part dels aprenents brasilers. Especialment, disminuint l'accent estranger, aspecte clau en la comunicació hispànico-brasilenya.

Paraules clau: entonació, espanyol, portugués, anàlisi melòdica

\begin{abstract}
This paper presents some of the results obtained in our research, in which we proposed to describe the patterns in the phonic speech integration as well as the melodic patterns and dispersion margins of the Spanish spoken by Brazilians. The results obtained through our study will make it possible to draw up a map of the intonational characteristics of the Spanish spoken by Brazilians, it will be possible to guide specific didactic actions that can improve the pronunciation of Spanish by Brazilians. Especially, decreasing the foreign accent, key in the Brazilian Hispanic communication.
\end{abstract}

Keywords: intonation, spanish, portuguese, melodic analysis 


\section{INTRODUCCIÓN}

Desde la perspectiva de la competencia comunicativa, ${ }^{1}$ la competencia fónica no puede ser entendida como algo añadido a posteriori sino como un elemento inherente a la propia competencia comunicativa, si consideramos que el primer componente lingüístico que adquirimos en nuestra L1 es la prosodia, dado que la entonación ejerce un papel primordial en la comunicación contribuyendo a la fragmentación del discurso en unidades semánticas menores, con el fin de facilitarle al receptor el procesamiento del mensaje (Cortés Moreno, 2002).

Para Cantero (2002) al hablar no emitimos sonidos unos después de los otros sino que estructuramos nuestro discurso siguiendo una jerarquía fónica donde las vocales son el eje principal, puesto que son los segmentos emitidos de forma conciente por el hablante. Por lo tanto, los sonidos no van sueltos sino integrados y jerarquizados en el discurso. Por esto se puede decir que los fenómenos entonativos (acento, ritmo y entonación) cumplen un papel determinante, tanto en la producción fónica como en la percepción de la lengua oral.

\section{METODOLOGÍA}

Para la realización del presente estudio se siguió el método Análisis Melódico del Habla propuesto por Cantero (2002). La obra ofrece un método de análisis formal (ver el protocolo de actuación en Cantero \& Font-Rotchés, 2009), centrado en el análisis y descripción de los patrones del habla espontánea, genuina, dado que pretende obtener una descripción fónica da real lengua oral. Esta metodología ya ha fundamentado diversas investigaciones sobre entonación. ${ }^{2}$

El referido modelo de análisis melódico del habla (Cantero, 2002) ofrece un referente teórico que proporciona una interpretación fonológica de los fenómenos tonales, además de un método de análisis formal, basado en el análisis acústico y perceptivo del discurso a través de medios instrumentales, con el fin de describir el fenómeno de la entonación desde un punto de vista fonético y fonológico (Font-Rotchés, 2004). Su punto de partida es la definición de la entonación como las variaciones de F0 que cumplen una función lingüística a lo largo de la emisión de voz (Cantero, 2002, p.18). Se considera que este fenómeno funciona en tres niveles: el prelingüístico, cohesionando el discurso; el lingüístico, distinguiendo unidades; y el paralingüístico, añadiendo información emocional (entre otras).

La entonación prelingüística engloba los fenómenos de acento, ritmo y entonación, que funcionan solidariamente como elementos fónicos que estructuran el discurso, al margen de cualquier otra dimensión significativa. En este nivel, Cantero (2002)

\footnotetext{
${ }^{1}$ [...] entendida, desde el pensamiento complejo, como un todo que va más allá de la suma de sus partes, con una perspectiva que contempla el carácter multilingüe de cualquier hablante, esto es, la interrelación de códigos que conforma la competencia de cada hablante: códigos verbales y no verbales, pero también las variedades lingüísticas que maneja el hablante -dialectales, de registro, etc.-, así como los distintos idiomas de los que -dado el caso- el hablante ha ido desarrollando algún tipo de interlengua. (Cantero, 2008).

2 Como los estudios de: Cantero et al., 2002 sobre el castellano; Font Rotchés, 2004, 2007 y Font Rotchés et al., 2002 sobre el catalán; Espuny, 1997 sobre el francés; además de otros relacionados con la adquisición y aprendizaje del español por chinos y taiwaneses: Cortés Moreno, 1999; Liu \& Cantero, 2002 y Liu, 2003.
} 
considera que la entonación actúa como un “contenedor" lingüístico, integrando y delimitando las unidades del discurso. Es lo que Quilis (1993) llamaba "función delimitadora” y "función integradora” de la entonación.

La entonación lingüística comprende las características melódicas cuyo rendimiento fonológico permite caracterizar y distinguir las unidades funcionales de la entonación, sus "signos lingüísticos". En el español, fueron identificados ocho tonemas (resultantes de la combinación de las características fonológicas: / \pm interrogativo, \pm suspendido, \pm enfático/), que normalmente son llamados de entonación neutra, interrogativa, suspendida y enfática (Cantero, 2002), cuyos patrones melódicos constituyen las melodías típicas del español descritas por Cantero \& Font-Rotchés (2007) totalizando doce patrones diferentes, con sus variantes y márgenes de dispersión.

Por fin, la entonación paralingüística, comprende las variantes melódicas de los referidos tonemas, dentro de los amplios márgenes de dispersión de cada un de ellos. Tales melodías permiten expresar emociones particulares, características discursivas idiolectales o de la personalidad del hablante e inclusive pueden estar variablemente codificadas.

Para la estructuración del presente estudio se partió de una fase teórica, seguida del análisis acústico de 361 contornos obtenidos de 12 informantes brasileños con fluidez en español. Como herramienta de análisis se utilizó el programa Praat ${ }^{3}$, el cual nos permite obtener los valores de la $\mathrm{F}_{0}$ de las vocales (en $\mathrm{Hz}$ ), estandardizarlos (es decir, establecer el porcentaje de subida y de bajada entre un valor tonal y el siguiente) y representarlos en gráficos, para así poder describir el español hablado por brasileños, aplicando la metodología de análisis melódico del habla (MAH) de Cantero (2002) y establecer comparaciones con la entonación propia del español hablado por nativos, (Navarro Tomás, 1944; Cantero et al., 2005, y Cantero \& Font-Rotchés, 2007).

\section{SELECCIÓN Y ANÁLISIS DE LOS ENUNCIADOS}

En el modelo utilizado para la investigación se distingue entre los rasgos melódicos y los rasgos fonológicos de la entonación: los rasgos melódicos constituyen el nivel fonético de análisis de la entonación, una vez eliminadas de la curva melódica todas las variaciones irrelevantes (micromelódicas) y normalizado sus valores (mediante su estandarización); los rasgos fonológicos, por su parte, permiten establecer los tonemas o unidades fonológicas de la entonación lingüística.

Se observan tres rasgos fonológicos binarios, cuya combinación permite caracterizar los tonemas de la lengua: / \pm Interrogativo/ / \pm Enfático/ / \pm Suspenso/

Los rasgos melódicos, por su parte, son las características acústicas de los elementos estructurales del contorno: el anacrusis, el primer pico, el cuerpo (o declinación) y la inflexión final.

\footnotetext{
3 Boersma \& Weenink (1992-2010) <http://www.praat.org >
} 


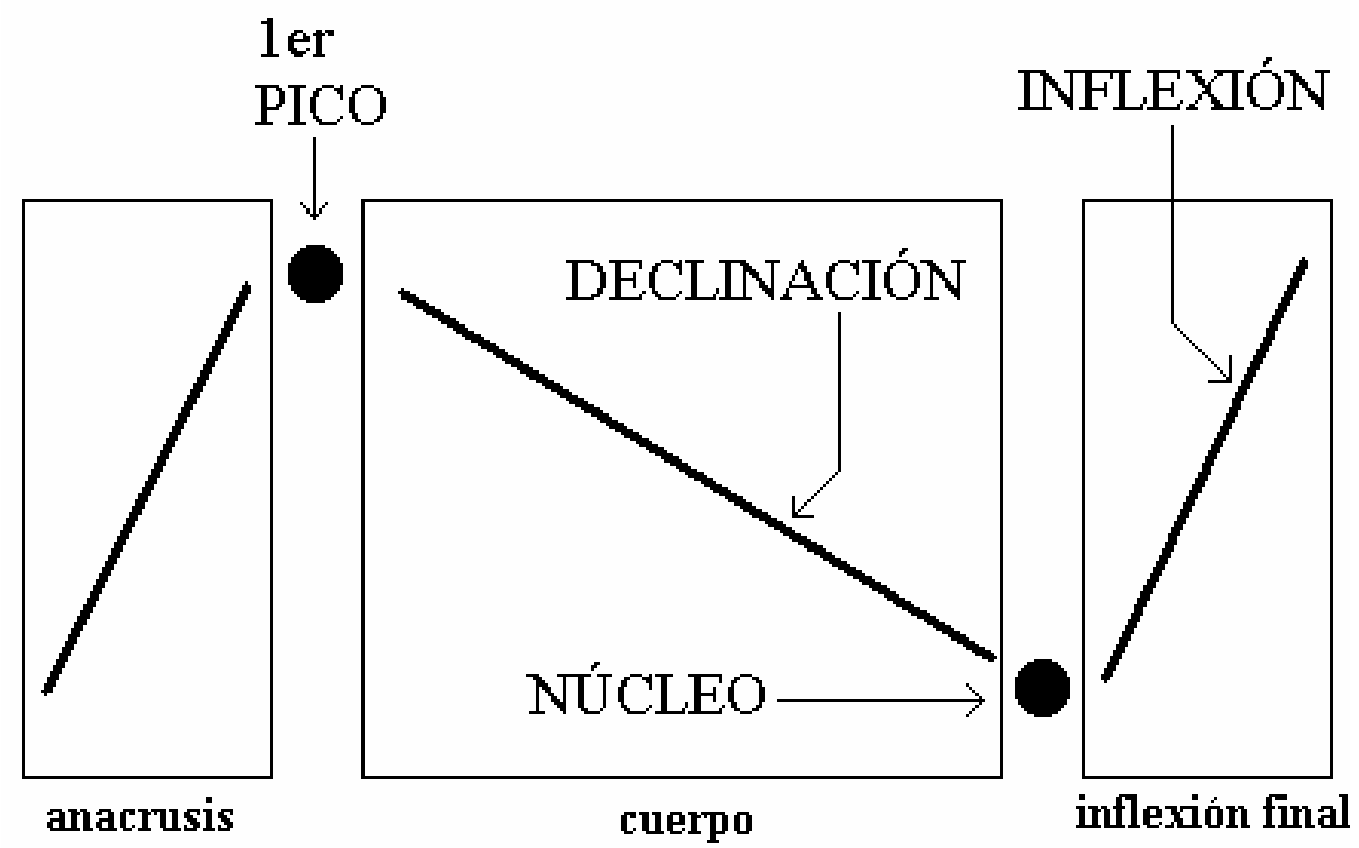

Figura 1 - Estructura del contorno entonativo (de Cantero \& Font-Rotchés, 2007)

Para la especificación de las características melódicas de las preguntas se describen primero los rasgos de la entonación prelingüística y luego la entonación lingüística.

Durante el análisis del corpus, compuesto por 361 enunciados, se verificó que las preguntas encontradas, en una primera aproximación no se asemejaban a los 4 patrones identificados como tonema /+interrogativo/ estudiados para el castellano, por Cantero \& Font-Rotchés (2007). Con este dato se decidió agrupar los enunciados que funcionaban como pregunta en su contexto comunicativo y a partir de ahí analizar sus características entonativas.

Inicialmente fueron identificadas 62 preguntas, que luego fueron ampliadas para 70 visto que se decidió analizar también las preguntas confirmativas, es decir aquellas que aparecen al final o en medio de enunciados neutros o suspendidos. Fueron definidos entonces como objeto de análisis 70 enunciados pregunta, pero con características distintas entre ellos, por lo tanto se procedió a la siguiente clasificación:

a- 24 preguntas absolutas, también llamadas totales, se caracterizan porque la pregunta comprende el contenido de todo el enunciado y se responden con un sí/no;

b- 15 preguntas parciales o pronominales (¿qué ha dicho?), que se focalizan en una parte del enunciado.

c- 31 preguntas confirmativas, que aparecen al final de los enunciados con un ¿no?, ¿'sabes?, etc. 
Estas últimas se asemejan a las tag question del inglés y en español suelen tener un ascenso mínimo, de modo qeue solo son "preguntas" desde un punto de vista semánticopragmático. Desde un punto de vista fonológico serían, probablemente, /+ suspensas/. Es importante observar que las preguntas confirmativas se sitúan al final o en medio de algunos enunciados clasificados como neutros, enfáticos, etc., por lo tanto son enunciados que también aparecen las demás clasificaciones.

En general en español, tampoco las "preguntas pronominales" suelen ser /+ interrogativas/, sino de entonación neutra (es decir, /- interrogativas/). Con todo, pese al valor fonológico de cada una, para fines de análisis el procedimiento de agrupación en la categoría "preguntas" facilitó la identificación de las características entonativas de dichos enunciados.

Así pues, el corpus total seleccionado es de 70 enunciados-pregunta producidos por 12 informantes 6 mujeres y 6 hombres- con edades comprendidas entre los 24 y los 49 años en el momento de la emisión de los enunciados. Todos ellos hablantes 'nativos' de las diversas variedades dialectales del portugués de Brasil, de nivel universitario concluido o en curso, con fluidez en español y en situación de inmersión de por lo menos dos años.

Después de la definición del corpus se procedió al análisis acústico y generación de los gráficos, los cuales fueron seleccionados de acuerdo con las categorías de ocurrencia de las preguntas en su contexto de emisión. Luego se analizó los rasgos melódicos de los contornos, es decir las características de la entonación prelingüística. En seguida focalizando la inflexión final de los enunciados se identificaron los patrones característicos de las preguntas analizadas y se hizo la comparación con los patrones melódicos del español peninsular presentados por Cantero et alii, 2002; Cantero y FontRotchés, 2007 que describen y establecen un total de doce patrones diferentes con sus variantes y márgenes de dispersión. Por fin los patrones hallados fueron comparados con los patrones melódicos identificados para el portugués de Brasil a través del Proyecto de investigación conjunta de la Universidad de Barcelona (UB) y la Universidade de Brasilia (UnB) Modelos de entonación del español y el portugués para la enseñanza de lenguas (A/016328/08) subvencionado por la Secretaria de Estado de Cooperación Internacional del Ministerio de Asuntos Exteriores de España. 


\section{ENTONACIÓN PRELINGÜÍSTICA}

Con relación a la entonación prelingüística se perciben los siguientes rasgos melódicos presentes en las preguntas analizadas:

- $\quad$ Ausencia de primer pico.

- Ausencia de declinación, todo es muy plano.

- Prominencias tonales en vocales átonas.

- Presencia de ligaduras internas.

\subsection{Primer pico}

En la mayoría de los enunciados no se identifica el primer pico, pero en algunos de ellos, es decir, es posible notarse indicios de un posible primer pico como en los ejemplos abajo:

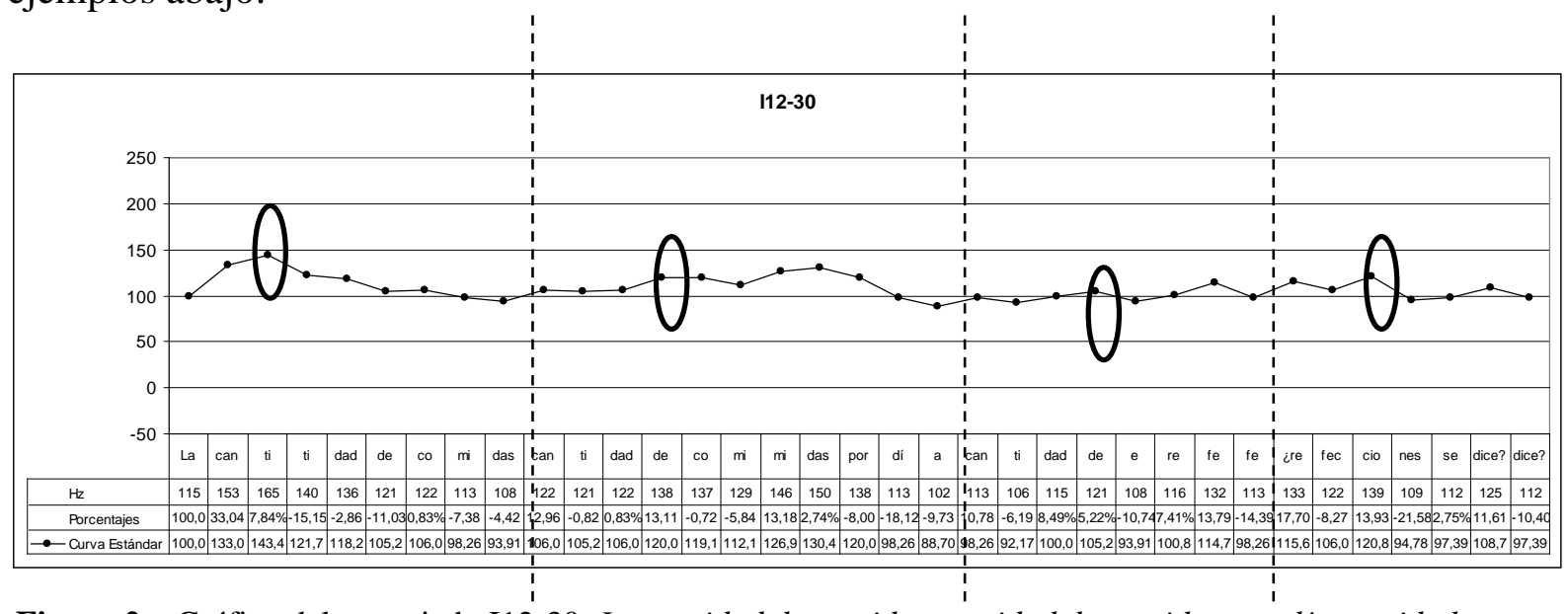

Figura 2 - Gráfico del enunciado I12-30: La cantidad de comidas cantidad de comidas por día cantidad de refe- ¿refecciones se dice?

El primer contorno presenta una prominencia tonal en la vocal pretónica "i" asemejándose a un primer pico, luego se percibe una declinación hasta el final de este contorno.

El segundo contorno presenta características un poco distintas al primero, el supuesto primer pico parece situarse en la primera vocal postónica, es decir, se asemeja a un primer pico desplazado, pero en este caso sólo se verifica una prominencia tonal sin inflexión.

El tercer contorno insinúa un primer pico también en la primera vocal postónica, pero en este caso hay inflexión.

El último contorno que funciona en el contexto como pregunta (I12-30d) presenta una prominencia tonal en la primera vocal átona con énfasis en la primera palabra asemejándose a un primer pico en la vocal tónica, la inflexión final es circunfleja con movimiento suave de subida y bajada 


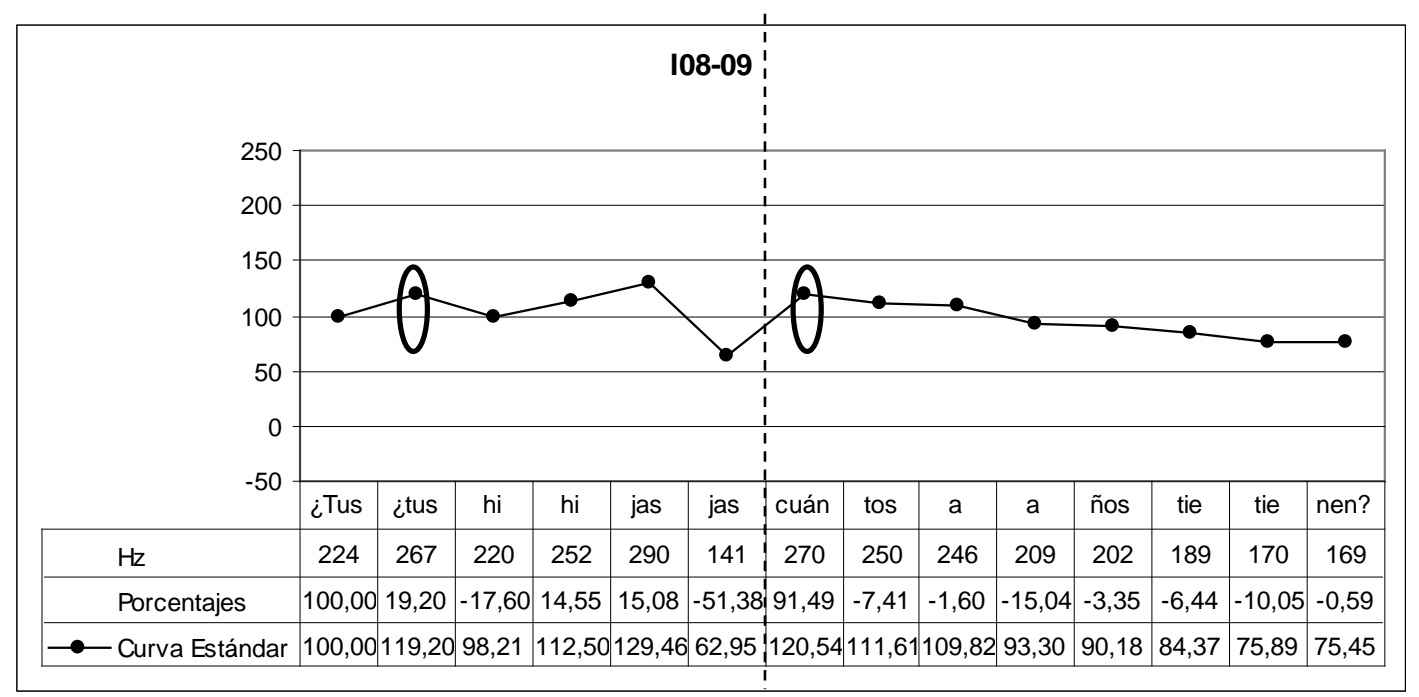

Figura 3 - Gráfico del enunciado I08-09: ¿Tus hijas cuántos años tienen?

El enunciado I08-09 se estructura en dos partes, en la primera parte se nota indicios de un primer pico en la primera prominencia tonal, es decir en la primera vocal átona. El segundo contorno que funciona como pregunta en el contexto discursivo presenta un contorno descendente a partir del primer segmento tonal lo cual se asemeja a un primer pico.

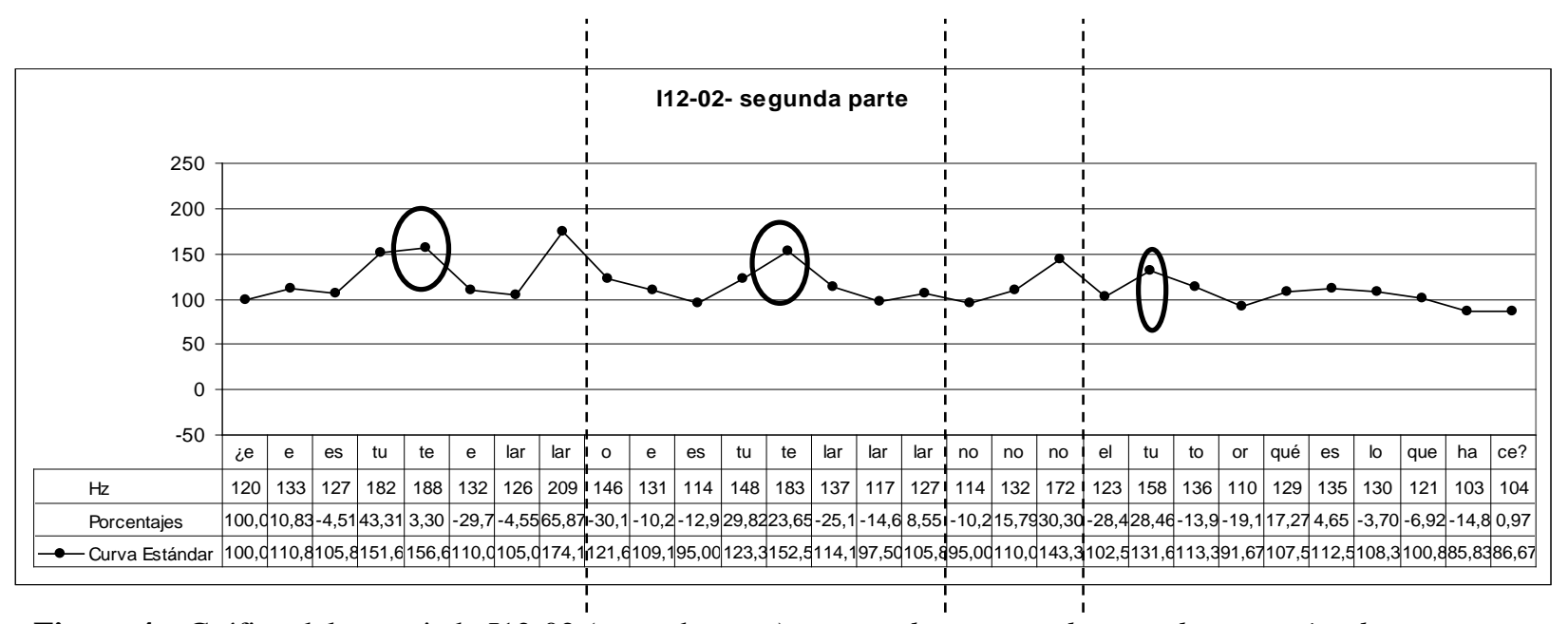

Figura 4 - Gráfico del enunciado I12-02 (segunda parte): ¿es tutelar o es tutelar, no el tutor qué es lo que hace?

Con relación al enunciado I12-02-segunda parte, en su primer contorno se percibe un primer pico en la vocal pretónica “e”. El segundo contorno repite el mismo primer pico en la vocal pretónica y en este caso coincide con el inicio de la inflexión final. En el tercer contorno no se nota indicios de primer pico, y en el cuarto contorno que funciona como pregunta se percibe la presencia del primer pico en la vocal átona pretónica. 


\subsection{Declinación}

Otra característica que fue posible observarse en los enunciados analizados fue la ausencia de declinación una vez que la mayoría de los enunciados no presentan primer pico. En muchos se nota una declinación muy plana con una tendencia a mantener la altura tonal de las primeras sílabas como en el enunciado siguiente:

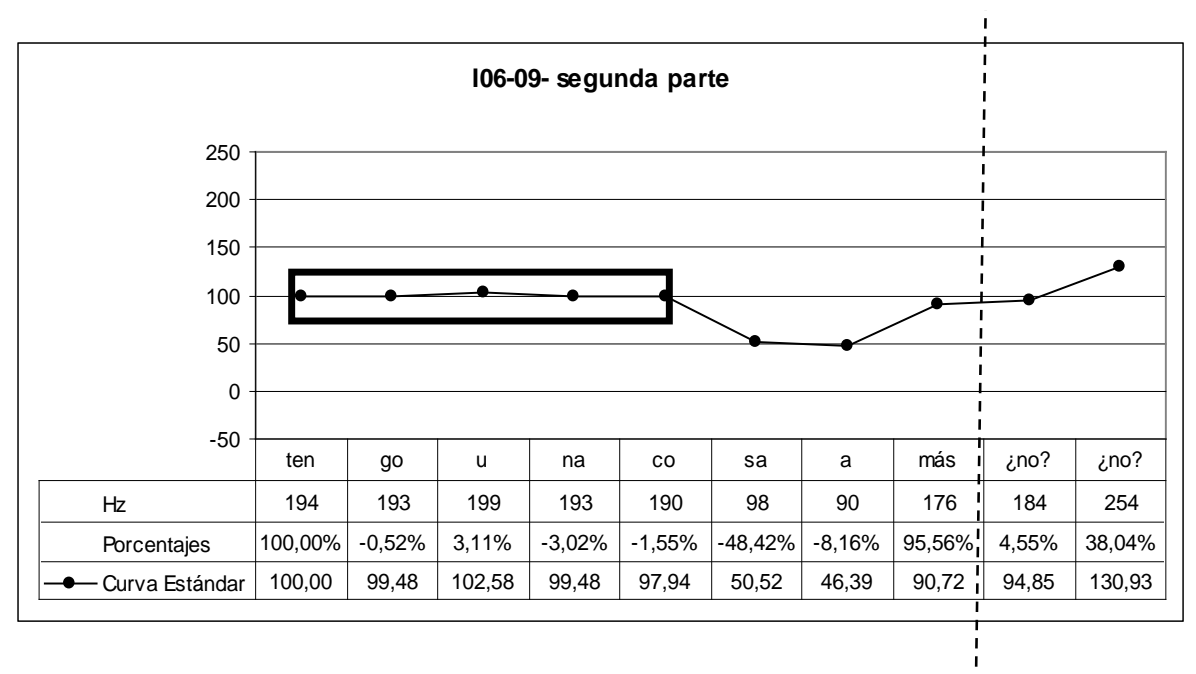

Figura 5 - Gráfico del enunciado I06-09 (segunda parte): Tengo una cosa a más ¿no?

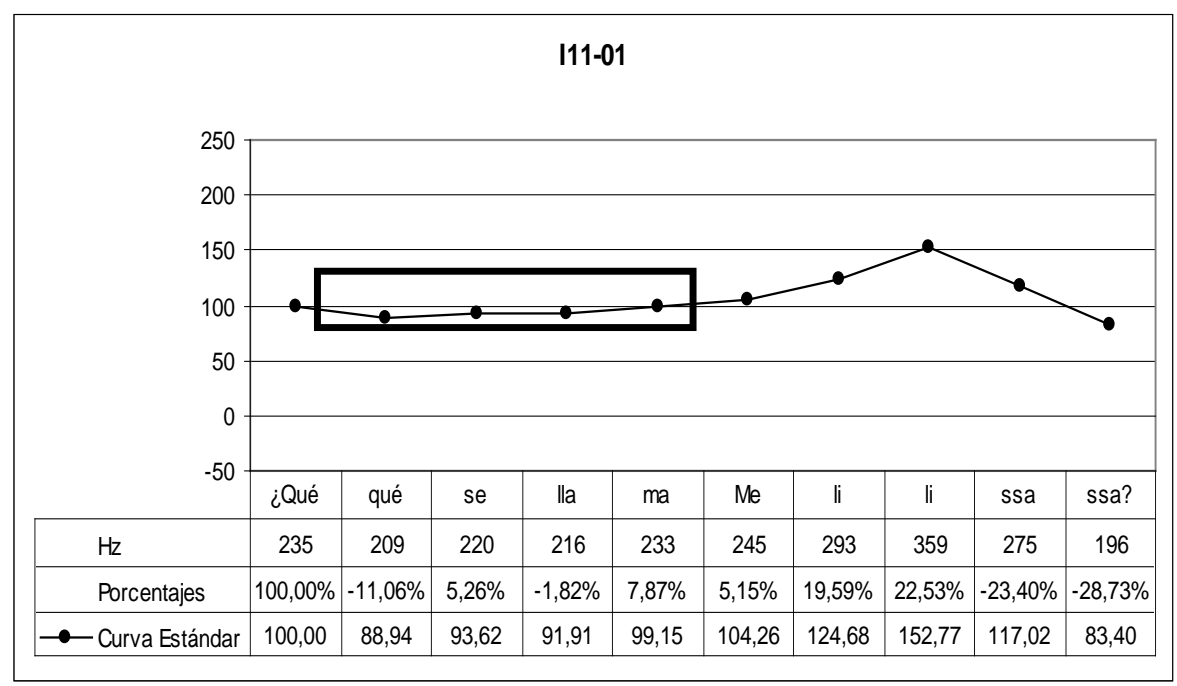

Figura 6 - Gráfico del enunciado I11-01: ¿Qué se llama Melissa? 


\subsection{Prominencias tonales en vocales átonas}

La presencia de prominencias tonales en vocales átonas ocurre en casi todos los enunciados analizados, parece ser un rasgo constante y característico de la entonación prelingüística del español hablado por brasileños.

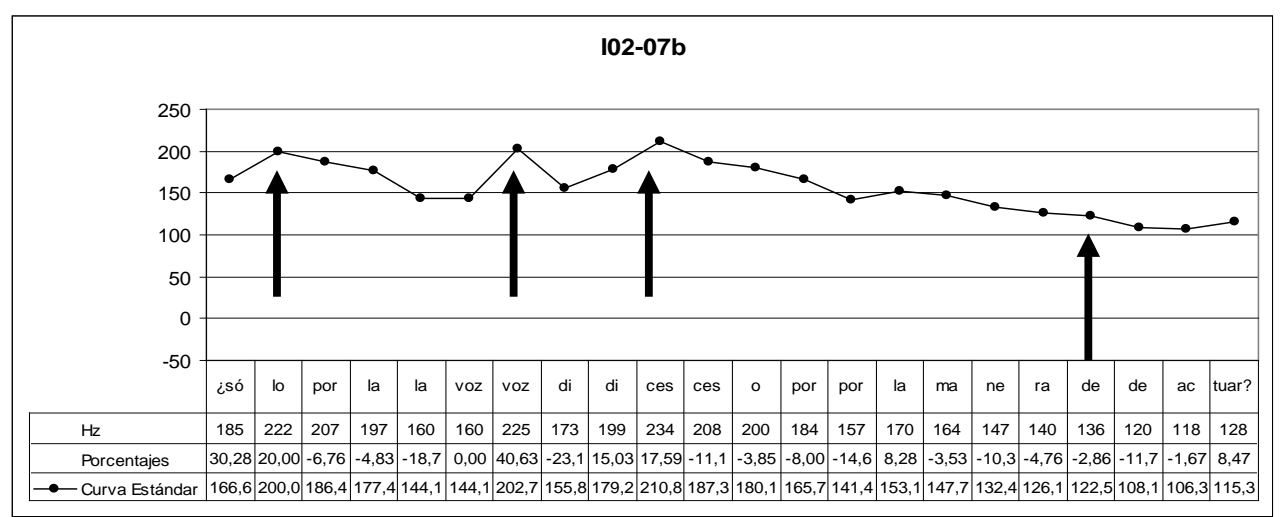

Figura 7 - Gráfico del enunciado I02-07b: ¿Sólo por la voz dices o por la manera de actuar?

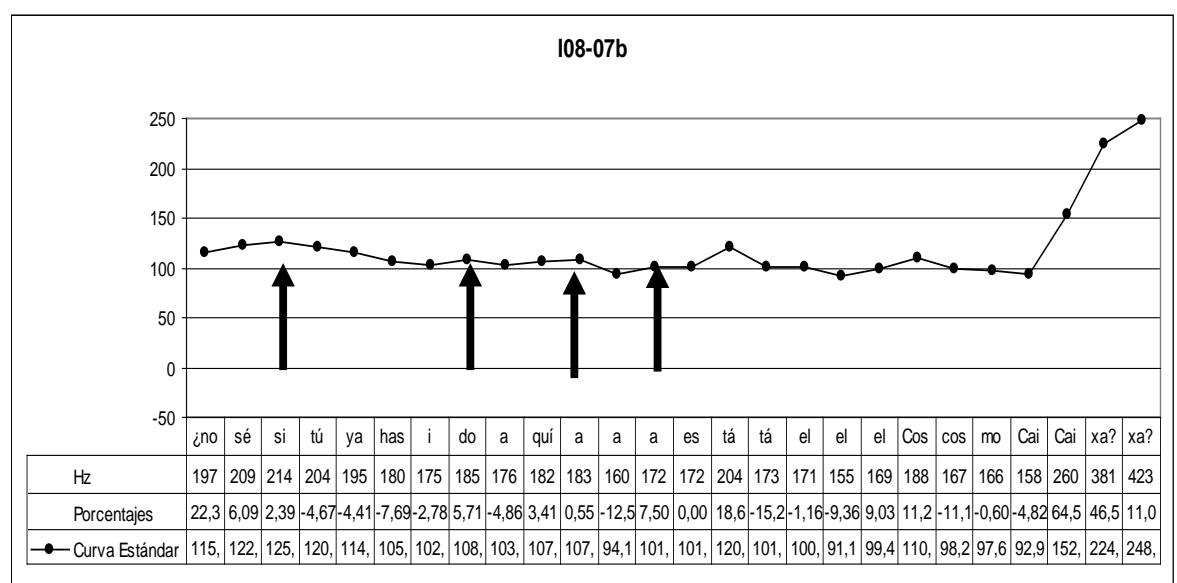

Figura 8 - Gráfico del enunciado I08-07b: ¿no sé si tú has ido aquí a está el Como Caixa? 


\subsection{Ligaduras internas.}

En el corpus analizado ocurren ligaduras tonales, es decir, inflexiones internas masivas, esto sumado a las prominencias de las vocales átonas produce contornos ondulados, dando en efecto perceptivo de sube y baja muy característico de la interlengua de los brasileños.

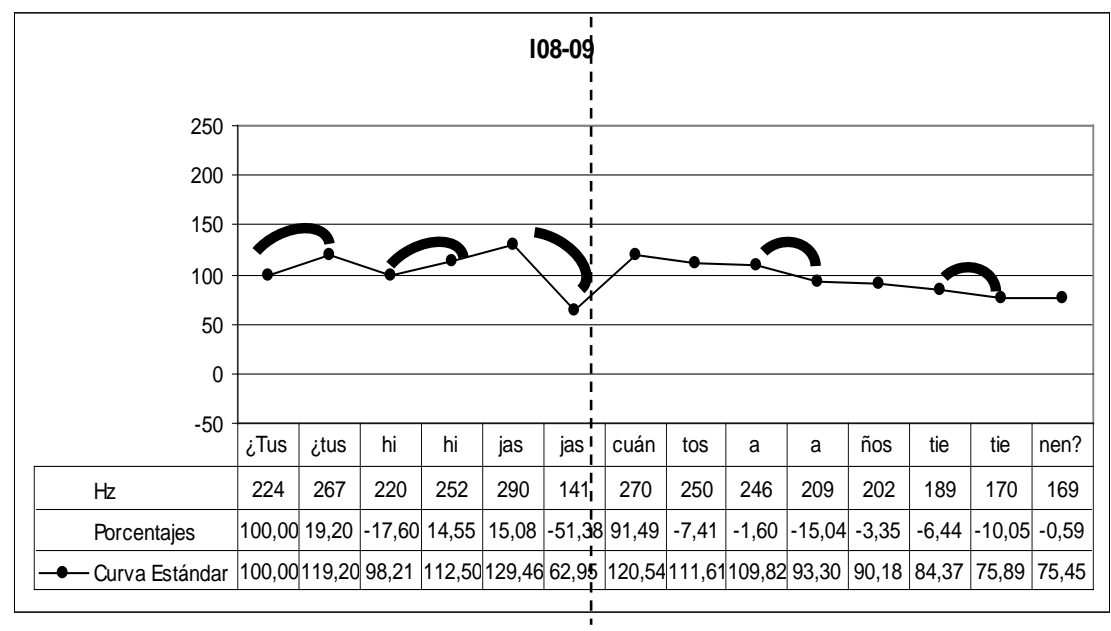

Figura 9 - Gráfico del enunciado I08-09: ¿Tus hijas cuántos años tienen?

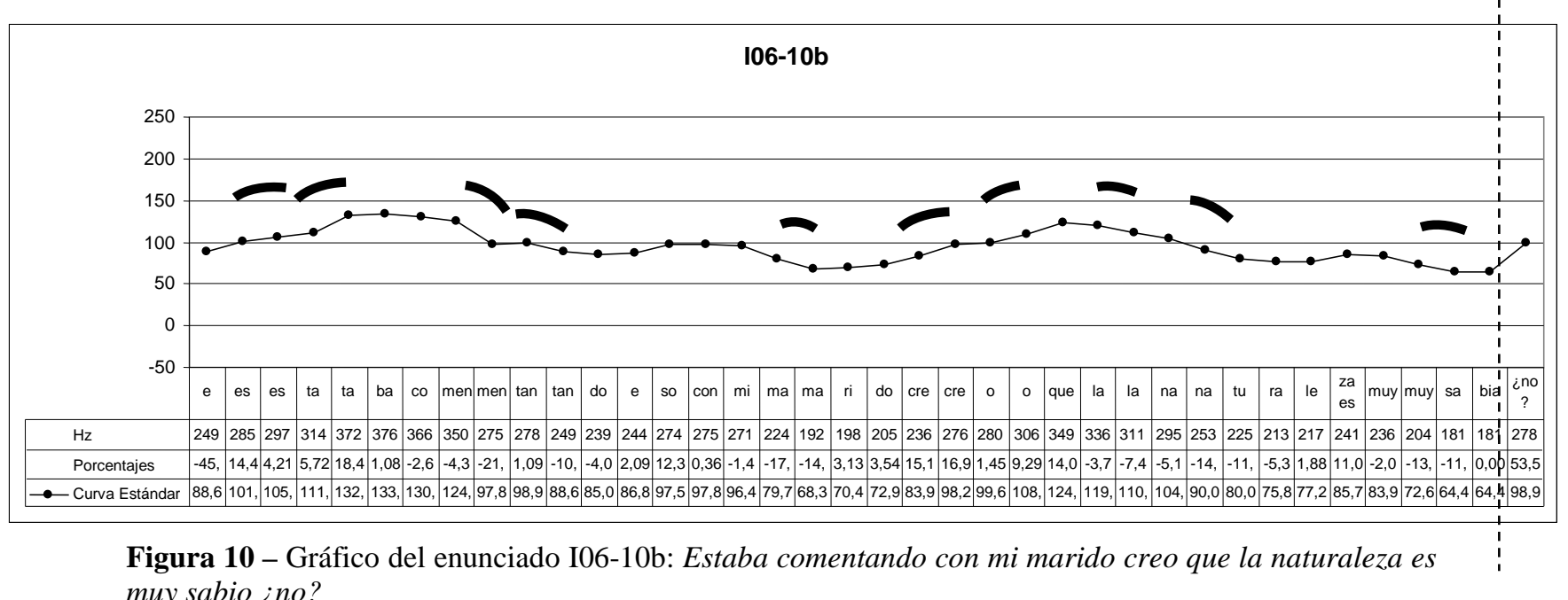

muy sabio ¿no? 


\section{ENTONACIÓN LINGÜÍSTICA DE LAS PREGUNTAS}

De acuerdo con Cantero (2002) la entonación lingüística representa el nivel de análisis en que podemos distinguir las unidades fonológicas de carácter suprasegmental capaces de diferenciar unidades de discurso significativas. Estas unidades fonológicas, denominadas tonemas, se caracterizan por los rasgos fonológicos (binarios): $1 \pm$ interrogativa/ / \pm enfática/ / \pm suspendida/. En Cantero (2002) se identificaron un total de 8 tonemas en español:
1. /+interrog. +enf. +susp./
5. /-interrog. +enf. +susp./
2. /+interrog. +enf. -susp./
6. /-interrog. +enf. -susp./
3. /+interrog. -enf. +susp./
7. /-interrog. -enf. +susp./
4. /+interrog. -enf. -susp./
8./ -interrog. -enf. -susp./

Cantero et al. (2002); Cantero \& Font-Rotchés (2007) identifican los doce patrones melódicos del español y Font-Rotchés \& Mateo (2011) describen un nuevo patrón melódico para producir oraciones interrogativas absolutas del español en habla espontánea el cual se caracteriza por una melodía ascendente desde el primero de los segmentos tonales que lo componen hasta el final del enunciado. Este es considerado el XIII patrón melódico del español:

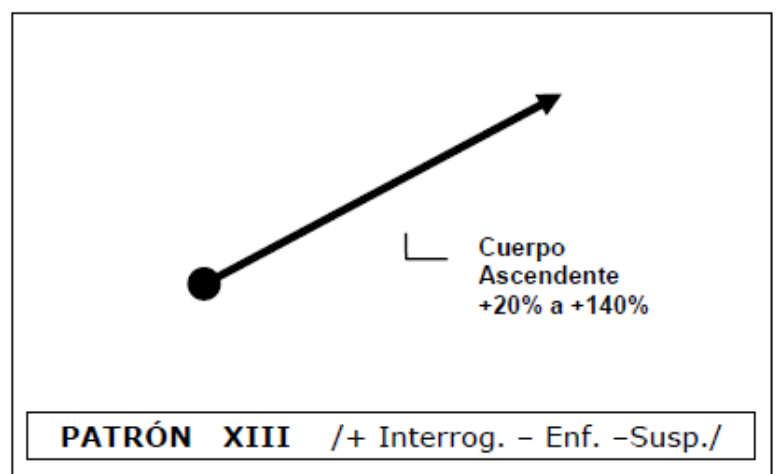

Figura 11 - Patrón melódico XIII (Font-Rotchés \& Mateo, 2011)

Con relación a la entonación lingüística de los enunciados clasificados como pregunta se pudo identificar inicialmente 9 patrones para las preguntas, siendo que 8 de ellos se repiten con frecuencia en el corpus analizado, a partir de dichos patrones se procedió a la comparación con los patrones melódicos del español y posteriormente con los patrones melódicos ya identificados para el portugués de Brasil. Las comparaciones con los patrones del español se hicieron esencialmente a través del análisis de sus inflexiones finales visto que la estructura de los contornos del corpus analizado no presenta en la mayoría de los casos los rasgos de los patrones melódicos descritos en español.

\subsection{Preguntas absolutas, pronominales y confirmativas}

En el corpus analizado, el 33\% de las preguntas absolutas se parecen al Patrón Melódico IVb/+int-enf-susp/. El 20\% se asemejan al Patrón Melódico II /+int-enf-susp/, el 25\% de preguntas absolutas se aproximan al Patrón Melódico XIIa/-int+enf-susp/. Además hay un ejemplo de pregunta con contorno semejante al Patrón Melódico III 
/+int-enf-susp/, un enunciado semejante al Patrón Melódico Xb/-int+enf-susp/, una pregunta parecida al Patrón Melódico Xb/-int+enf-susp y dos enunciados con contorno semejante al patrón melódico V/-int-enf+susp/ lo que representa el 8\% de los enunciados.

En síntesis las preguntas absolutas se clasifican de la siguiente forma: el 57\% de las preguntas se asemejan al tonema /+interrogativo/ del español, el 33\% al tonema /+enfático/ y el 8\% al tonema /+suspendido/.

Las preguntas pronominales totalizan 15 enunciados de estos:

4 se asemejan al Patrón Melódico XIIa/-int+enf-susp/ - 26\%. 3 se parecen al Patrón Melódico Xb/-int+enf-susp/ - 20\%. 1 presenta semejanza con el Patrón Melódico Xb/int+enf-susp/ - 6\%. 3 son se asemejan al Patrón Melódico V/-int-enf+susp/ - 20\%. 2 se parecen con el Patrón Melódico VIb/-int-enf+susp/ - 13\%. 3 no que se parecen a ningún Patrón Melódico del español, pero se asemejan al patrón melódico C del portugués de Brasil - 20\%

En resumen, el $52 \%$ de las preguntas parciales o pronominales suenan como /+enfáticas/, el 33\% como /+suspendidas/ y el 20\% suenan directamente como en portugués el patrón melódico C /+interrogativo/.

Con relación a las preguntas confirmativas, pese a que en español acostumbran a ser /+suspendidas/, en el español hablado por brasileños el $48 \%$ de los casos se asemejan al tonema /+interrogativo/, el 12\% son /+enfáticos/ y el 38,7\% son /+suspendidos/.

\subsection{Preguntas hechas con entonación enfática}

La entonación enfática fue la más frecuente de los tonemas identificados siendo el Patrón Melódico Xb del español el más utilizado.

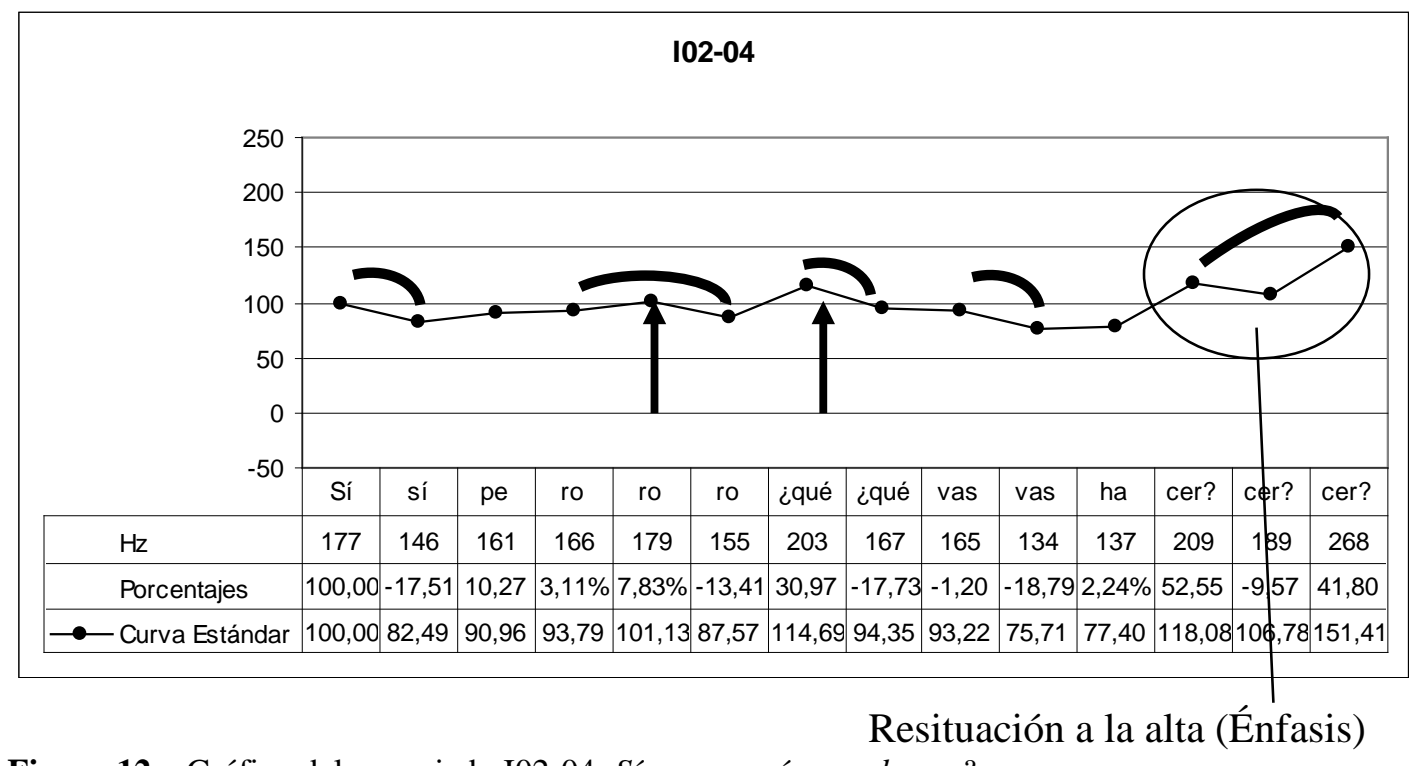

Figura 12 - Gráfico del enunciado I02-04: Sí pero ¿qué vas a hacer? 
La primera parte del enunciado presenta un contorno entonativo semejante al PATRÓN MELÓDICO Xa / I + E -S/ solo que con un ascenso y un descenso muy suaves lo que hace parecer más a una suspendida que no a una enfática. La segunda parte del enunciado donde ocurre la pregunta presenta también ligaduras internas y una inflexión final circunfleja con una resituación a la alta con características semejantes al PATRÓN MELÓDICO Xb /- I + E -S/ entonación enfática pero sin los demás rasgos característicos de este patrón.

\subsection{Preguntas hechas con entonación interrogativa}

El segundo tonema más frecuente entre los enunciados clasificados como pregunta fue el interrogativo, siendo el patrón melódico II el más recurrente. Siguen abajo los ejemplos de enunciados interrogativos encontrados en el corpus.

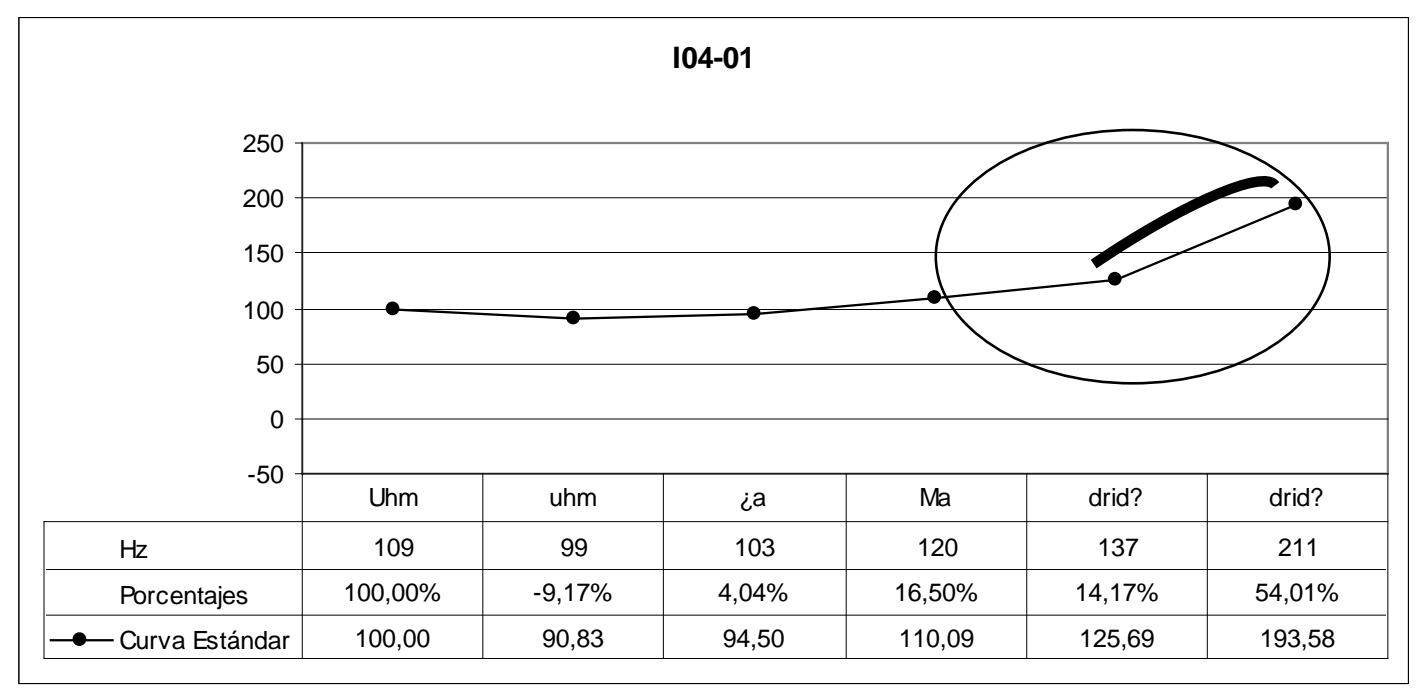

Figura 13 - Gráfico del enunciado I04-01: Uhm ¿a Madrid?

En el enunciado arriba se percibe el inicio de una subida en la última vocal pretónica seguida por una inflexión final de 68,18\% asemejándose al PATRÓN MELÓDICO II /+ I- E -S/.

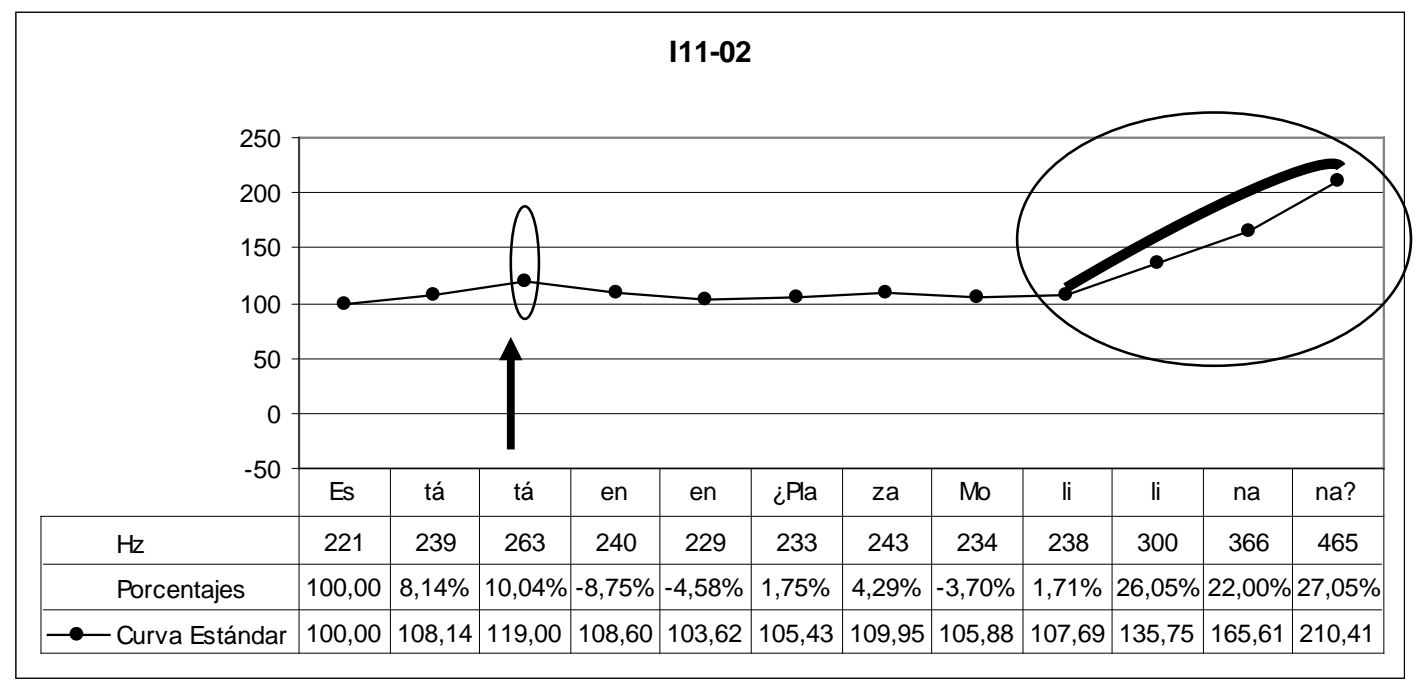

Figura 14 - Gráfico del enunciado I11-02: Está en ¿Plaza Molina? 
El enunciado arriba presenta una inflexión final con una subida total de 75,1\%, asemejándose al PATRÓN MELÓDICO II /+ I - E -S/.

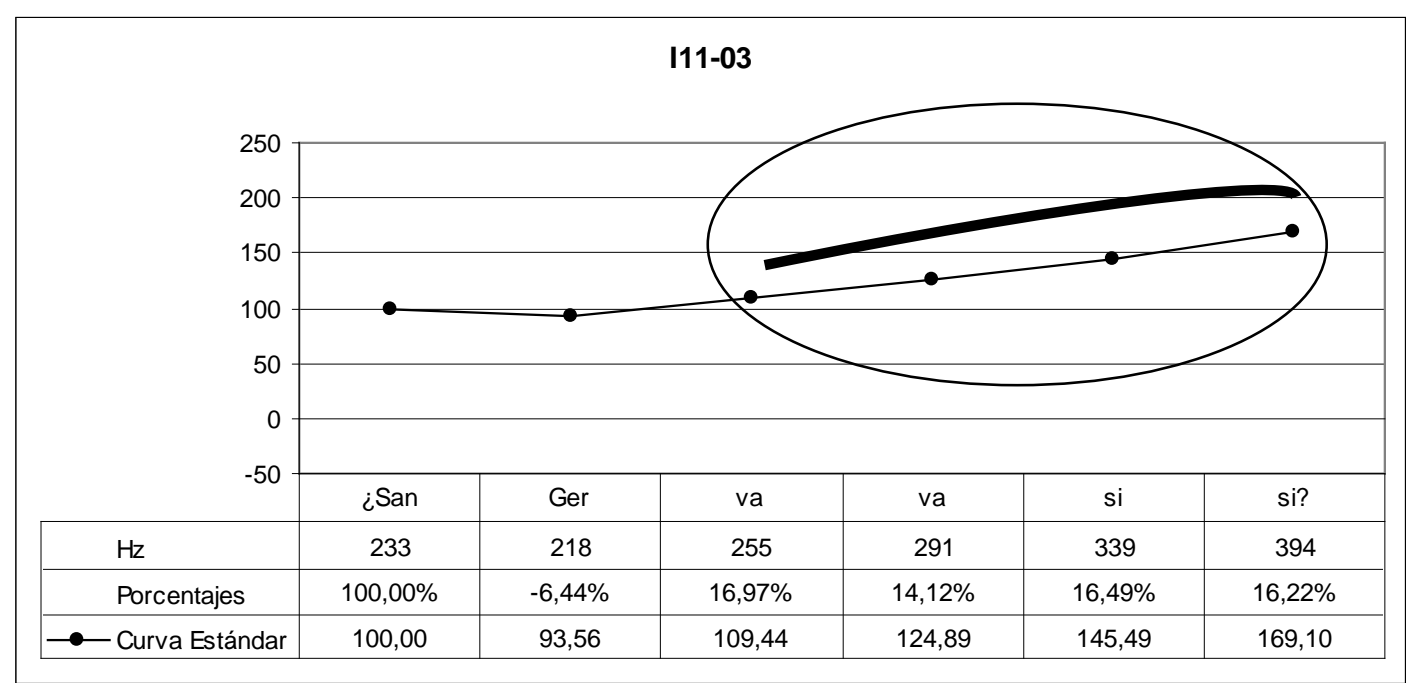

Figura 15 - Gráfico del enunciado I11-03: ¿San Gervasi?

La pregunta arriba presenta una subida final de 63,77\% aproximándose del PATRÓN MELÓDICO II /+ I - E -S/ pero solo con relación al ascenso final pues no se identifican las demás características de este patrón melódico en el enunciado.

\subsection{Preguntas hechas con entonación suspendida}

Se identificó un 20\% de enunciados con características del tonema /+S/.

Ejemplo:

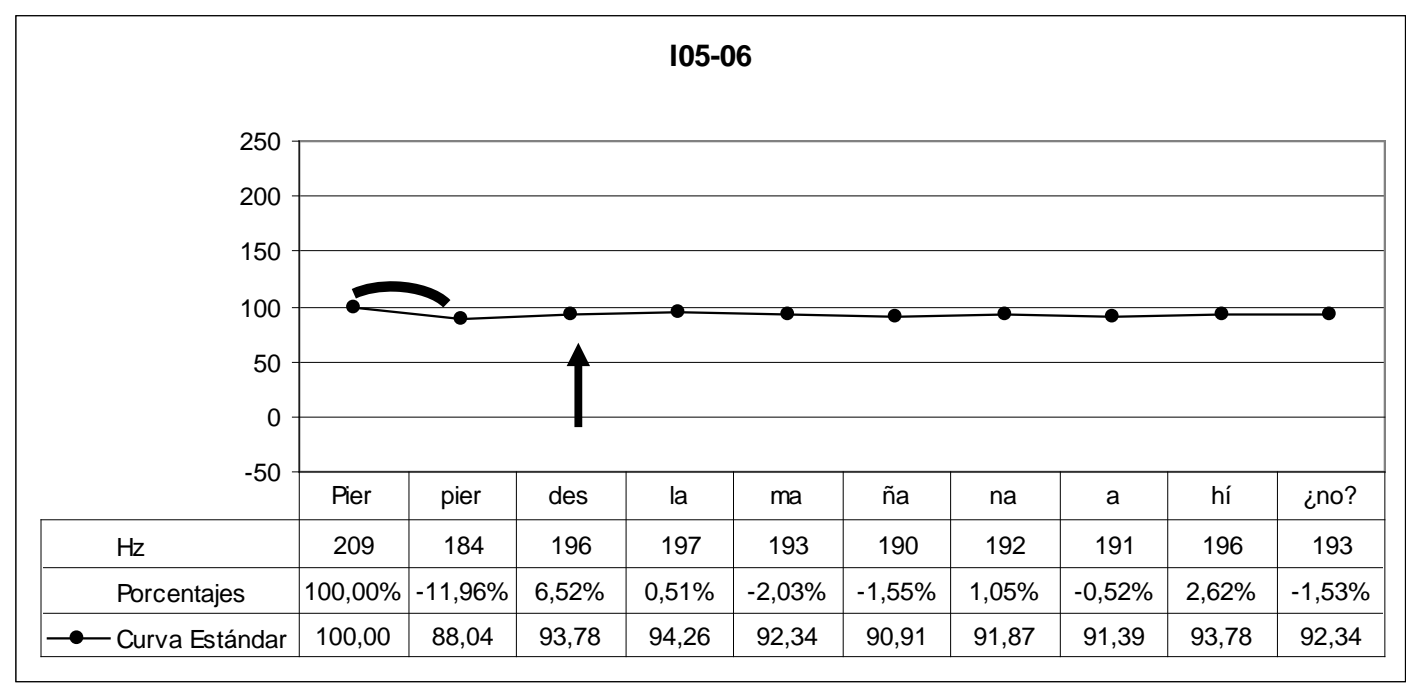

Figura 16 - Gráfico del enunciado I05-06: Pierdes la mañana ahó ¿no?

Contorno entonativo plano, con una prominencia tonal en vocal átona y ligadura en el primer segmento, no hay inflexión final y pese a funcionar como pregunta en su contexto se asemeja al PATRÓN MELÓDICO V / - I - E +S/ entonación suspendida. 


\subsection{Preguntas hechas con entonación neutra}

En los enunciados identificados con el tonema /- I - E -S/, es decir, los que presentan una entonación neutra, en general, tienen una inflexión final poco marcada si comparada con lo que ocurre en español, podrían confundirse en muchos casos como suspendidas por ser muy planas.

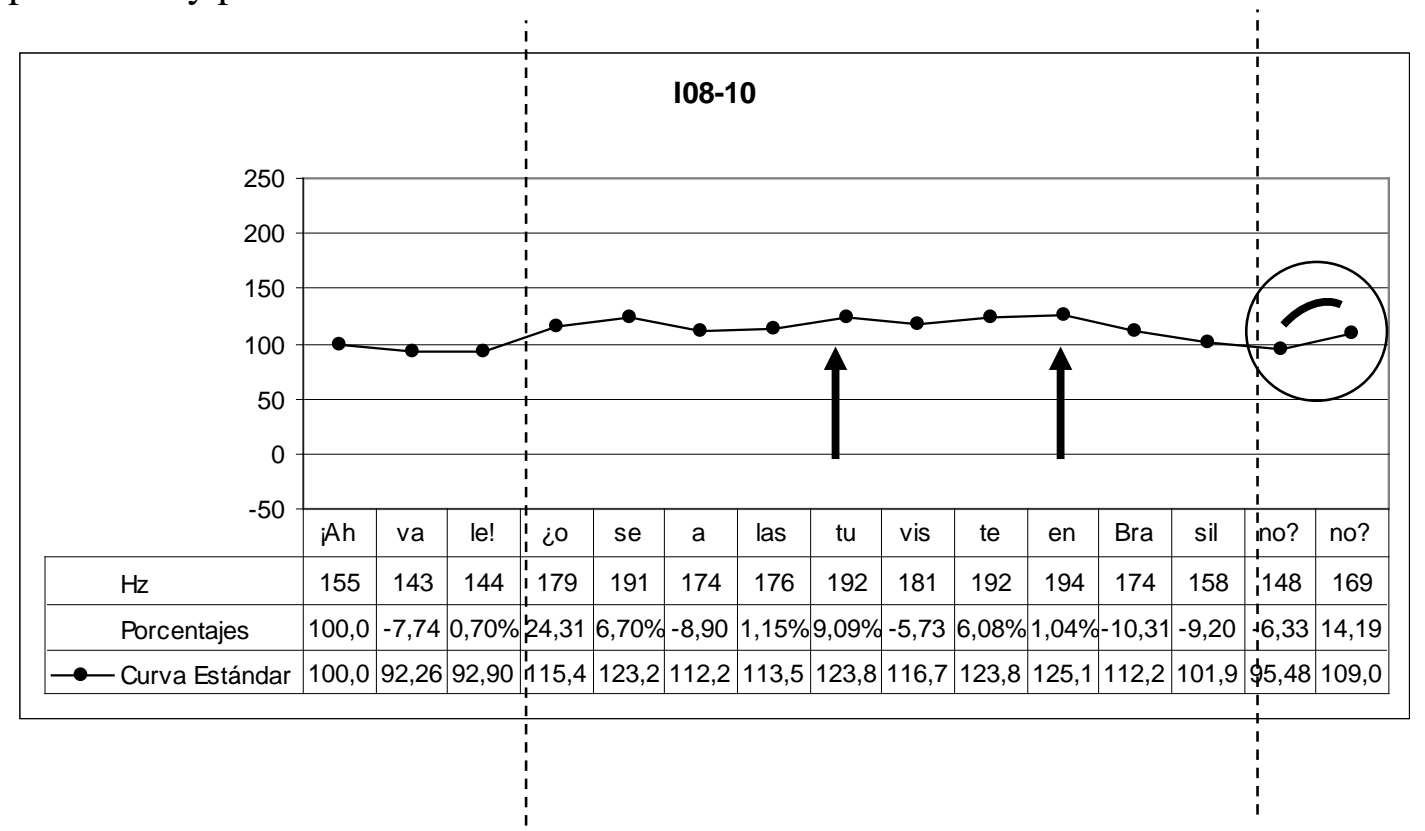

Figura 17 - Gráfico del enunciado I08-10: ¡Ah vale! ¿o sea las tuviste en Brasil?

En el enunciado I08-10 se identifican tres partes. La primera se asemeja con el PATRÓN MELÓDICO V / - I- E +S/ entonación suspendida, sin inflexión final. La segunda parte presenta prominencias tonales en vocales átonas, a partir de la segunda prominencia se nota la bajada de 19,51\% asemejándose a una neutra PATRÓN MELÓDICO I / - I - E -S/. La parte final dónde ocurre la pregunta hay una subida de apenas un 14,19\% asemejándose también al PATRÓN MELÓDICO I / - I - E -S/ entonación neutra.

\section{CONCLUSIÓN}

A través del análisis de las preguntas presentes en el corpus se identificaron características típicas de la entonación prelingüística del español hablado por brasileños, siendo los rasgos más marcados la presencia de prominencias tonales en vocales átonas y ligaduras internas que dan movimientos a los contornos entonativos. En general, no se identifica la ocurrencia de primer pico, lo que en español marca el inicio de un grupo fónico, visto que es la primera vocal tónica del enunciado. Parece ser que los grupos fónicos se estructuran de forma diferente al español. Cuando se percibe la presencia de indicios de primer pico, este no ocurre en la primera vocal tónica sino en la pretónica y también en la postónica. Al no haber primer pico, no hay una declinación clara a lo largo del enunciado, lo que hace con que ocurran melodías muy planas, pero contornos ondulados causados por las presencia constante de prominencias y ligaduras internas.

En los enunciados largos se perciben contornos interiores enfáticos, neutros y algunas veces suspendidos, lo que sería lo más frecuente en español, se nota en ellos prominencia en la vocal pretónica y por veces postónica. 
No hay una regularidad en las prominencias tonales, apareciendo por veces en la vocal pretónica, otras en la postónica y algunas veces en las dos.

En cuanto a la entonación prelingüística, la organización del discurso es en parte extraña en español ya que no hay primer pico, no hay declinación, los contornos internos son muchas veces enfáticos, con frecuentes prominencias y ligaduras. Todo eso configura el "perfil melódico" (Cantero \& Devís, 2011) del español hablado por brasileños, lo que caracteriza su "acento extranjero".

En cuanto a la entonación lingüística, se nota el uso frecuente del tonema /+I/ pero no se perciben todos los rasgos característicos de cada patrón melódico, lo que haría que estos enunciados fueran interpretados como enfáticos, dificultando la comunicación entre hablantes brasileños y españoles.

Se observa también el uso de la entonación enfática para hacer preguntas, hecho que podría causar extrañamiento entre los interlocutores nativos de español, que podrían no conseguir interpretar los enunciados como pregunta. Las suspendidas y neutras directamente no serían interpretadas como preguntas por hablantes españoles. Todas estas diferencias pueden generar malentendidos, visto que una pregunta puede entenderse como un énfasis o como una frase inacabada.

Pese a que las diferencias diagnósticas en la entonación del español hablado por brasileños no impide la comunicación con los nativos, sí puede dificultar en alguna medida la fluidez en los intercambios comunicativos, por eso la identificación de estas características proporcionan herramientas para ayudar a orientar adecuadamente los enfoques didácticos del español para brasileños.

\section{REFERENCIAS BIBLIOGRÁFICAS}

Boersma, Paul y David Weenink (1992-2018): PRAAT. Doing phonetics by computer. Institute of Phonetic Sciences, University of Amsterdam. [disponible en http://www.praat.org].

Cantero Serena, Francisco José (2002): Teoría y análisis de la entonación. Barcelona: Edicions de la Universitat de Barcelona.

Cantero Serena, Francisco José (2008): “Complejidad y Competencia Comunicativa”, Revista Horizontes de Lingüística Aplicada, v. 7, n. 1, p. 71-87,

Cantero Serena, Francisco José \& Empar Devís (2011): “Análisis melódico de la interlengua”, en A. Hidalgo; Y.Congosto \& M Quilis (eds.): El estudio de la prosodia en España en el siglo XXI: perspectivas y ámbitos. Anejo ${ }^{\circ} 75$ de la Revista Quaderns de Filologia. Universitat de València. (pp. 285-299).

Cantero Serena, Francisco José \& Dolors Font-Rotchés (2007): "Entonación del español peninsular en habla espontánea: patrones melódicos y márgenes de dispersión”. Moenia, 13, p.69-92.

Cantero Serena, Francisco José \& Dolors Font-Rotchés (2009): "Protocolo para el análisis melódico del habla”. Estudios de Fonética Experimental, XVIII. p. 17-32.

Cantero Serena, Francisco José, Raúl Alfonso, Marta Bartolí, Anna Corrales y Maribel Vidal (2005): «Rasgos melódicos de énfasis en español», Phonica, vol. 1 
Cantero Serena, Francisco José; M. A. de Araújo; Y.H. Liu; Y.K. Wu \& A. Zanatta (2002): "Patrones melódicos de la entonación interrogativa del español en habla espontánea", Actas del II Congreso de Fonética Experimental. Sevilla: Univ. Sevilla. Págs. 118-123.

Cortés Moreno, Maximiano (1999): Adquisición de la entonación española por parte de hablantes nativos de chino. Tesis doctoral - Barcelona: Departament de Didàctica de la Llengua i la Literatura, Universitat de Barcelona.

Cortés Moreno, Maximiano (2002): Didáctica de la prosodia del español: la acentuación y la entonación. Madrid: Edinumen.

Espuny, Janina (1997): “Aspects prosodiques du discurs hétérogène diaphonique”, Estudios de Fonética Experimental, VIII, p- 271-295.

Font-Rotchés, Dolors (2004): Prosòdia, Articles, núm 32. Págs. 25-38.

Font-Rotchés, Dolors (2007): L'entonació del català. Barcelona: Publicacions de l'Abadia de Montserrat.

Font-Rotchés, Dolors; Canals, Anna; Ester, Glòria; Hermoso, Adoración \& Cantero Serena, Francisco José (2002): "Patrones melódicos de la entonación interrogativa del catalán en habla espontánea”, Actas del II Congreso de Fonética Experimental, Universidad de Sevilla.

Font-Rotchés, Dolors; Mateo-Ruiz, Miguel (2011): «Absolute interrogatives in Spanish, a new melodic pattern». Actas del VII Congresso Internacional da ABRALIN. Curitiba, pp. 1111-1125.

Liu, Yen-Hui (2005): La entonación del español hablado por taiwaneses, Biblioteca Phonica, 2. www.ub.es/lfa

Liu, Yen Hui \& Cantero Serena, Francisco José (2002): “La entonación prelingüística del español hablado por taiwaneses: Establecimiento de un corpus”. Actas del II Congreso de Fonética Experimental, Universidad de Sevilla.

Navarro Tomás, Tomás. (1944): Manual de entonación española, New York: Hispanic Society. (1974): Madrid, Guadarrama. 